\title{
Clinical outcomes after treatment of multiple lesions with zotarolimus-eluting versus sirolimus- eluting coronary stents (a SORT OUT III substudy)
}

Troels Thim ${ }^{1,7^{*}}$, Michael Maeng ${ }^{1}$, Jens Flensted Lassen ${ }^{1}$, Anne Kaltoft ${ }^{1}$, Lisette Okkels Jensen ${ }^{2}$, Jan Ravkilde ${ }^{3}$, Per Thayssen², Søren Galatius ${ }^{4}$, Evald Høj Christiansen ${ }^{1}$, Thomas Engstrøm ${ }^{5}$, Morten Madsen ${ }^{6}$, Leif Thuesen ${ }^{1}$ and Hans Henrik Tilsted ${ }^{3}$

\begin{abstract}
Background: Data on clinical outcomes among patients treated with the zotarolimus-eluting Endeavor ${ }^{\mathrm{TM}}$ stent versus the sirolimus-eluting Cypher ${ }^{\mathrm{TM}}$ stent favor the sirolimus-eluting stent. However, a separate comparison of clinical outcome among patients treated for multiple lesions with these stents is lacking. We performed this comparison within the SORT OUT III trial data set.

Methods: Among 2332 patients randomized in SORT OUT III, 695 were treated for multiple lesions with zotarolimus-eluting ( $n=350)$ or sirolimus-eluting $(n=345)$ stents and followed for 18 months. Major adverse cardiac events (MACE); composite of cardiac death, myocardial infarction, or target vessel revascularization (TVR); was the primary endpoint.

Results: Zotarolimus-eluting compared to sirolimus-eluting stent treatment was associated with increased MACE rate (13.2\% vs. 2.6\%; hazard ratio 5.29 with $95 \%$ confidence interval: 2.59-10.8). All secondary endpoints; all cause death, cardiac death, myocardial infarction, TVR, target lesion revascularization, in-stent restenosis, and definite stent thrombosis; were observed more frequently among zotarolimus-eluting stent treated patients. For all endpoints, hazard ratios were 1.6 to 4.6 times higher than in the overall results of the SORT OUT III trial.

Conclusions: We observed better clinical outcomes among patients treated for multiple lesions with the sirolimuseluting stent compared to those treated with the zotarolimus-eluting stent.
\end{abstract}

\section{Background}

Percutaneous coronary intervention (PCI) with drug eluting stent (DES) implantation in single coronary artery lesions has become mainstay [1]. Gradually, PCI with DES of multiple coronary artery lesions, concomitantly, has increased, and PCI of multiple lesions in patients with multivessel disease is under evaluation as an alternative or supplement to coronary artery bypass surgery [2].

In some stent trials with comparison of zotarolimuseluting and sirolimus-eluting stents, however, stent safety and efficacy have only been evaluated in patients with single lesions [3]. In other trials and registry

\footnotetext{
* Correspondence: troels.thim@ki.au.dk

'Department of Cardiology, Aarhus University Hospital, Aarhus, Denmark Full list of author information is available at the end of the article
}

studies, patients with single and multiple lesions have been analyzed together [4-6]. Trials comparing the zotarolimus-eluting Endeavor ${ }^{\mathrm{TM}}$ stent and the sirolimuseluting Cypher ${ }^{\mathrm{TM}}$ stent generally favor the sirolimuseluting stent [7]. However, a separate analysis of data on patients treated for multiple lesions has not been reported. Considering the current use of DES to treat multiple lesions concomitantly, such a separate analysis is relevant. In the SORT OUT III trial, we compared clinical outcome among all-comers randomized to the zotarolimus-eluting Endeavor ${ }^{\mathrm{TM}}$ stent and the sirolimuseluting Cypher ${ }^{\mathrm{TM}}$ stent [5]. In this trial, patients with multiple lesions were included. Here, we make a separate comparison of clinical outcomes among patients treated for multiple lesions with zotarolimus-eluting and sirolimus-eluting stents in the SORT OUT III trial.

\section{C) Biomed Central}




\section{Methods}

This study was approved by the local ethics committee and complied with the Declaration of Helsinki. Patients provided written, informed consent before participation. The SORT OUT III trial was registered with ClinicalTrials.gov (NCT00660478).

In the framework of the SORT OUT organization, we undertook the SORT OUT III trial; a multi-centre, open-label, randomized, all-comer trial from January 2006 through August 2007 in five Danish high-volume PCI centers [5]. We included patients 18 years or older undergoing PCI. Patients were eligible when they needed DES stent treatment of at least one coronary lesion. There were no upper limits on the number of treated lesions, treated vessels, or lesion length. When more than one lesion required treatment, the allocated study stent should be used to treat all lesions. Exclusion criteria were: inability to provide informed consent; life expectancy of less than one year; allergy to acetylsalicylic acid, clopidogrel, ticlopidine, sirolimus, or zotarolimus; or participation in another randomised trial. Concurrent diseases or advanced age did not preclude participation.

In this substudy, we analyzed clinical outcomes among patients undergoing PCI for multiple lesions (more than one) at the index PCI. When PCI of more than one lesion was needed, non-allocated DES or bare metal stents were only implanted if the allocated study stent could not be implanted.

At the time of the index PCI, we recorded cardiovascular risk factors and comorbidity and calculated Charlson comorbidity score $[8,9]$.

Using a telephone allocation service, we randomized patients after diagnostic coronary angiography and before PCI. With block randomization according to center, patients were randomized 1:1 to receive either the zotarolimus-eluting (Endeavor, Medtronic, Santa Rosa, CA) or the sirolimus-eluting (Cypher Select or Cypher Select+; Cordis, Johnson \& Johnson, Warren, NJ) stent. Patients were stratified by gender and the presence or absence of diabetes. Patients were pre-treated with at least $75 \mathrm{mg}$ acetylsalicylic acid, a 300-600 mg loading dose of clopidogrel, and 5,000 IU or 70-100 IU/kg unfractionated heparin. After PCI, dual antiplatelet regimens with lifelong acetylsalicylic acid, $75 \mathrm{mg}$ daily, and clopidogrel, $75 \mathrm{mg}$ daily, for one year, was recommended in accordance with Danish guidelines [10].

Clinical outcomes were assessed at 18 months. The primary endpoint was major adverse cardiac events (MACE) defined as a composite endpoint of cardiac death, myocardial infarction, and target vessel revascularization (TVR). Other endpoints were all-cause death, cardiac death, myocardial infarction, TVR, target lesion revascularization (TLR) (within the stent $+5 \mathrm{~mm}$ in proximal and distal directions), symptom-driven observation of in-stent restenosis (within the stent +5 $\mathrm{mm}$ in proximal and distal directions), and definite stent thrombosis. These endpoints have been described previously [5].

Data on mortalilty (cardiac and non-cardiac), hospital admissions, coronary angiography, repeat PCI, and coronary bypass surgery were obtained from national Danish registries (Danish Civil Registration System, National Registry of Causes of Death, Danish National Registry of Patients, the local heart registries in the five PCI centers, and the Danish Heart Register) [11-17]. These cover the entire Danish population.

Independent study monitors, blinded to treatment assignment, reviewed all repeat coronary examinations and interventions (coronary angiography, coronary balloon angioplasty, coronary stent implantation, and coronary artery bypass surgery) and classified their cause as in-stent restenosis or stent thrombosis based on review of angiograms and patient files. An independent endpoint committee, also blinded to treatment assignment, reviewed all events and classified all myocardial infarctions and deaths.

Continuous variables with a normal distribution were analyzed using the two-sample $t$-test (Cochran $t$-test if the variances were unequal) and continuous variables with a non-normal distribution using the Mann-Whitney $U$ test. Categorical variables were analyzed using the Chi-square test. Endpoints were counted in the followup period starting on the date of the index PCI. For each endpoint, follow up continued until occurrence of the endpoint event, death, emigration, or until 18 months after stent implantation. We estimated relative risks using Cox proportional hazards regression analysis. In the analyses, patients receiving the sirolimus-eluting stent served as reference group. Analyses were performed according to the intention-to-treat principles. We used SAS software version 9.2 (SAS Institute Inc., Cary, NC, USA) and $p<0.05$ was considered statistically significant.

\section{Results}

Among the 2,332 patients randomized to zotarolimuseluting or sirolimus-eluting stents in the SORT OUT III trial, 695 received PCI for multiple $(>1$ ) lesions at the index PCI. Of these, 350 were allocated to zotarolimuseluting stents and 345 were allocated to sirolimus-eluting stents. Baseline patient characteristics were wellbalanced between the zotarolimus-eluting and sirolimuseluting stent groups with the exception of previous PCI which was more common among those receiving zotarolimus-eluting stents (Table 1). In total, 810 lesions were treated in the zotarolimus-eluting stent group and 787 lesions were treated in the sirolimus-eluting stent group with similar lesion and procedure data, except for a 


\begin{tabular}{|c|c|c|c|}
\hline & $\begin{array}{l}\text { Zotarolimus-eluting } \\
\text { stent }(\mathrm{n}=350)\end{array}$ & $\begin{array}{l}\text { Sirolimus-eluting } \\
\text { stent }(\mathrm{n}=345)\end{array}$ & $\mathrm{p}$ \\
\hline Age (years) & $64.8(10.3)$ & $64.5(10.4)$ & 0.71 \\
\hline Men & $271(77.4 \%)$ & $269(78.0 \%)$ & 0.86 \\
\hline Family history of coronary artery disease & $154(44.9 \%)$ & $141(41.6 \%)$ & 0.38 \\
\hline Current smokers & $94(28.1 \%)$ & $100(30.9 \%)$ & 0.44 \\
\hline Diabetes mellitus & $44(12.6 \%)$ & $52(15.1 \%)$ & 0.34 \\
\hline Body mass index $\left(\mathrm{kg} / \mathrm{m}^{2}\right)$ & $27.5(5.6)$ & $27.2(4.6)$ & 0.44 \\
\hline Hypertension & $203(59.0 \%)$ & $178(52.7 \%)$ & 0.10 \\
\hline Hypercholesterolemia & $243(70.4 \%)$ & $233(68.7 \%)$ & 0.63 \\
\hline Previous myocardial infarction & $130(37.7 \%)$ & $129(38.4 \%)$ & 0.84 \\
\hline Previous percutaneous coronary intervention & $72(20.9 \%)$ & $48(14.2 \%)$ & 0.02 \\
\hline Previous coronary artery bypass surgery & $16(4.6 \%)$ & $18(5.3 \%)$ & 0.68 \\
\hline Charlson comorbidity score & & & 0.35 \\
\hline 0 & $232(66.3 \%)$ & $211(61.2 \%)$ & \\
\hline 1 or 2 & $98(28.0 \%)$ & $109(31.6 \%)$ & \\
\hline 3 or more & $20(5.7 \%)$ & $25(7.2 \%)$ & \\
\hline Indication for intervention & & & 0.19 \\
\hline Stable angina pectoris & $195(55.7 \%)$ & $177(51.3 \%)$ & \\
\hline ST-segment elevation myocardial infarction & $13(3.7 \%)$ & $16(4.6 \%)$ & \\
\hline Unstable angina pectoris or non-ST-segment elevation myocardial infarction & $129(36.9 \%)$ & $146(42.3 \%)$ & \\
\hline Other & $13(3.7 \%)$ & $6(1.7 \%)$ & \\
\hline
\end{tabular}

Categorical variables are presented as counts (frequency in percent) and continuous variables as means (standard deviation)

small difference in the distribution of the number of treated lesions per patient (Table 2).

The assigned study stent could not be implanted in 1 lesion in a patient allocated to the zotarolimus-eluting stent and in 11 lesions in patients allocated to the sirolimus-eluting stent. This was a statistically significant difference in stent deliverability (Table 2).

All endpoints occurred more frequently in patients treated with zotarolimus-eluting stents (Table 3, Figure 1). For MACE, all cause death, myocardial infarction, TVR, TLR, and in-stent restenosis, the differences were statistically significant. For cardiac death and definite stent thrombosis, the differences were not statistically significant but the hazard ratios were high and in favor of the sirolimus-eluting stent (6.97 and 4.01, respectively).

\section{Discussion}

In the present SORT OUT III sub-study, we observed better clinical outcomes among patients treated for multiple lesions with the sirolimus-eluting stent compared to those treated with the zotarolimus-eluting stent. The difference was consistent across all endpoints. Thereby, this study extends findings from previous studies to patients in need of intervention for multiple lesions [7].

Comparing the difference in clinical outcomes in the current analysis with the overall SORT OUT III study results [5], higher hazard ratios were observed for all endpoints. The hazard ratio for MACE was more than two times higher than in the overall results. The hazard ratios for all other endpoints were 1.6 (in-stent restenosis) to 4.6 (cardiac death) times higher than in the overall results. In accordance with the overall results, the outcome differences were statistically significant for MACE, all cause death, myocardial infarction, TVR, TLR, and in-stent restenosis while the differences were not statistically significant for cardiac death and definite stent thrombosis.

The observed larger difference in outcome in patients treated for multiple lesions compared to the overall results supports the relatively consistent findings in favor of the sirolimus-eluting stent [18]. Our findings are also in agreement with a subgroup analysis of the SPIRIT III trial. In SPIRIT III, the outcome among patients treated with the everolimus-eluting stent (XIENCE V) and the paclitaxel-eluting stent (TAXUS) were compared favoring the everolimus eluting stent [19]. In a subgroup analysis of patients treated for 2-vessel disease in SPIRIT III, patients treated for 2-vessel disease had a larger outcome difference in favor of the everolimus-eluting stent compared to those treated for 1-vessel disease [20].

With a true outcome difference in patients with single lesions, a similar or even more favorable outcome difference in patients with multiple lesions in general then seems likely. However, there may be effects that could not have been predicted from studies on patients with single lesions and therefore subgroup analyses or specifically designed studies should be performed in patients 
Table 2 Lesion and procedure data

\begin{tabular}{|c|c|c|c|}
\hline & Zotarolimus-eluting stent $\mathrm{n}=\mathbf{8 1 0}$ & Sirolimus-eluting stent $\mathrm{n}=787$ & $\mathrm{p}$ \\
\hline Number of treated lesions per patient & & & 0.04 \\
\hline 2 & $230(65.7 \%)$ & $254(73.6 \%)$ & \\
\hline 3 & 91 (26.0\%) & $63(18.3 \%)$ & \\
\hline$>3$ & $29(8.3 \%)$ & $28(8.1 \%)$ & \\
\hline Number of treated vessels per patient & & & 0.21 \\
\hline 1 & 115 (32.9\%) & $107(31.0 \%)$ & \\
\hline 2 & $188(53.7 \%)$ & $207(60.0 \%)$ & \\
\hline 3 & $47(13.4 \%)$ & $31(9.0 \%)$ & \\
\hline Target lesion coronary artery & & & 0.45 \\
\hline Left main & $17(2.1 \%)$ & $13(1.7 \%)$ & \\
\hline Left anterior descending & $308(38.0 \%)$ & $267(33.9 \%)$ & \\
\hline Left circumflex & $222(27.4 \%)$ & $229(29.1 \%)$ & \\
\hline Right & $261(32.2 \%)$ & $276(35.1 \%)$ & \\
\hline Bypass graft & $2(0.2 \%)$ & $2(0.3 \%)$ & \\
\hline Lesion type & & & 0.09 \\
\hline A & $156(19.3 \%)$ & $136(17.5)$ & \\
\hline B & $336(41.6 \%)$ & $365(47.1)$ & \\
\hline C & $316(39.1 \%)$ & $274(35.4)$ & \\
\hline Length of stented segment per lesion (mm) & $19.5(11.4)$ & $19.7(12.2)$ & 0.77 \\
\hline Length of stented segment per patient (mm) & $45.2(20.8)$ & 44.9 (20.9) & 0.87 \\
\hline Maximal stent diameter $(\mathrm{mm})$ & $3.2(0.5)$ & $3.2(0.5)$ & 0.84 \\
\hline Use of glycoprotein IIb/Illa inhibitors & $75(21.4 \%)$ & $87(25.2 \%)$ & 0.24 \\
\hline Assigned study stent could not be implanted & $1(0.1 \%)$ & $11(1.4 \%)$ & 0.003 \\
\hline
\end{tabular}

Categorical variables are presented as counts (frequency in percent) and continuous variables as means (standard deviation)

with multiple lesions. Also, any trial can be associated with a type 1 error, and confirmation of a trial result in similar or associated settings is always settling.

The different event rates observed could be caused by differences in drugs, drug release kinetics, polymers, or other factors related to stent design. Any of these parameters could affect plaque or vessel wall healing and thus have impact on the results. This study, however, was not designed to assess these mechanisms. Likewise, differences in stent deliverability may be attributed to many factors in stent design.

There are some limitations to our study. The SORT OUT III parent study was powered to assess the composite clinical endpoint, MACE, at 9-month followup [5]. Therefore, this sub-study relying on the SORT OUT III data after 18 months of follow-up was not necessarily powered to assess the examined endpoints. As well, the results obtained in this study for the rapidrelease Endeavor ${ }^{\mathrm{TM}}$ stent cannot be extrapolated to other zotarolimus-eluting stents such as the slow-release Resolute $^{\mathrm{TM}}$ stent [21]. The SORT OUT III trial [5], like the SORT OUT II trial [22], relied on registry-based event detection without study-related angiographic or clinical follow-up. Patient follow-up care was in accordance with normal clinical practice, i.e., a standard clinical outpatient visit at the referring hospital after 1-3

Table 3 Clinical endpoints

\begin{tabular}{lccc}
\hline & $\begin{array}{c}\text { Zotarolimus-eluting } \\
\text { stent }(\mathbf{n}=\mathbf{3 5 0 )}\end{array}$ & $\begin{array}{c}\text { Sirolimus-eluting } \\
\text { stent }(\mathbf{n}=\mathbf{3 4 5})\end{array}$ & $\begin{array}{c}\text { Hazard ratio } \\
\text { (95\% confidence interval) }\end{array}$ \\
\hline Major Adverse Cardiac Events & $46(13.2 \%)$ & $9(2.6 \%)$ & $5.29(2.59-10.8)$ \\
All cause death & $16(4.6 \%)$ & $5(1.5 \%)$ & $3.20(1.17-8.72)$ \\
Cardiac death & $7(2.0 \%)$ & $1(0.3 \%)$ & $6.97(0.86-56.6)$ \\
Myocardial infarction & $12(3.4 \%)$ & $1(0.3 \%)$ & $12.1(1.57-92.8)$ \\
Target vessel revascularization & $37(10.6 \%)$ & $8(2.3 \%)$ & $4.79(2.23-10.3)$ \\
Target lesion revascularization & $32(9.2 \%)$ & $4(1.2 \%)$ & $8.31(2.94-23.5)$ \\
In-stent restenosis & $24(6.9 \%)$ & $3(0.9 \%)$ & $8.23(2.48-27.3)$ \\
Definite stent thrombosis & $8(2.3 \%)$ & $2(0.6 \%)$ & $4.01(0.85-18.9)$ \\
\hline
\end{tabular}



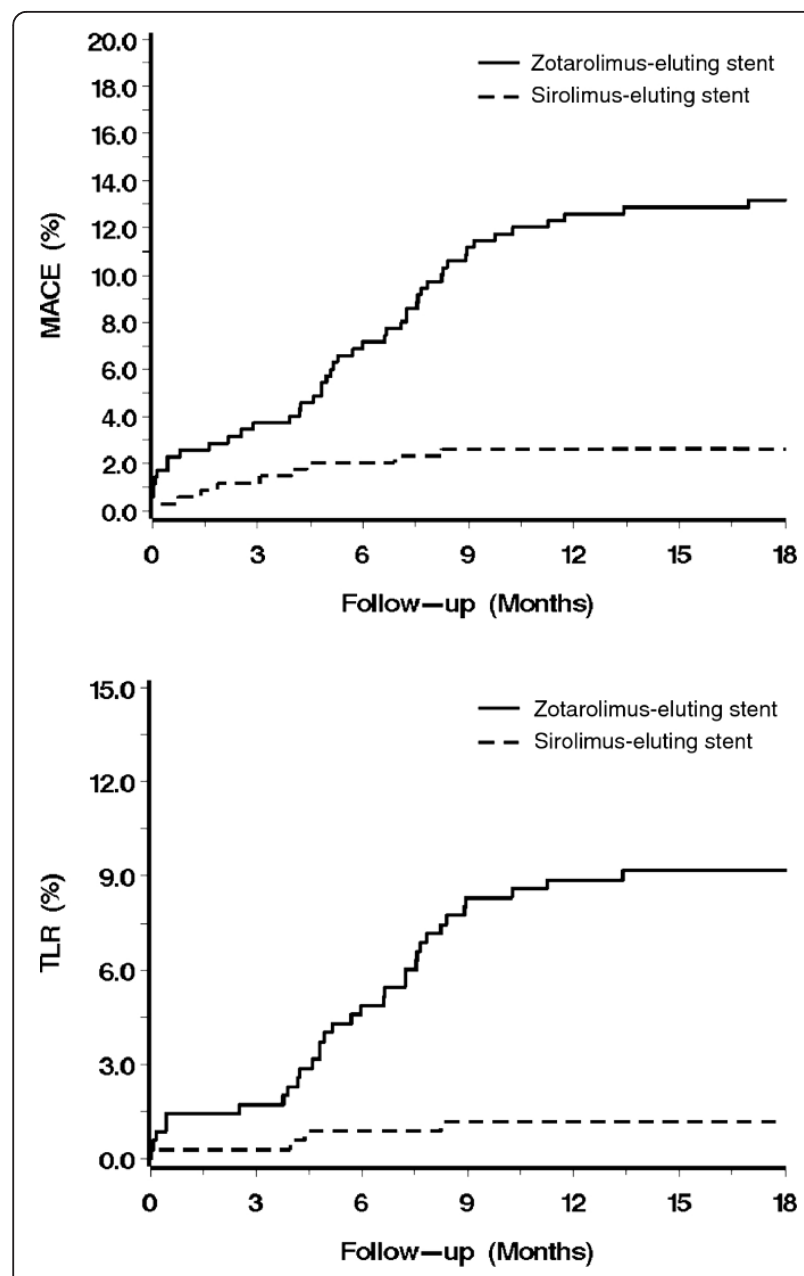

Figure 1 Major adverse cardiac events (MACE) and target lesion revascularization (TLR) Kaplan-Meier curves. MACE encompassed cardiac death, myocardial infarction, and target vessel revascularization. months. This patient-driven event detection reflects event presentation in routine clinical practice where patients need to contact the heath care system. This methodology thus differs from event detection based on study-driven telephone calls or visits at outpatient clinics.

\section{Conclusions}

We observed better clinical outcomes among patients treated for multiple lesions with the sirolimus-eluting stent compared to those treated with the zotarolimuseluting stent.

\section{Abbreviations}

$\mathrm{PCl}$ : percutaneous coronary intervention; DES: drug eluting stent(s); MACE: major adverse cardiac events; TVR: target vessel revascularization; TLR: target lesion revascularization.

\section{Acknowledgements}

This work was supported by unrestricted grants from Cordis and Medtronic.

\section{Author details}

'Department of Cardiology, Aarhus University Hospital, Aarhus, Denmark. 2Department of Cardiology, Odense University Hospital, Odense, Denmark. ${ }^{3}$ Department of Cardiology, Aarhus University Hospital Aalborg, Aalborg, Denmark. ${ }^{4}$ Department of Cardiology, Gentofte University Hospital, Copenhagen, Denmark. ${ }^{5}$ Department of Cardiology, Rigshospitalet, Copenhagen University Hospital, Copenhagen, Denmark. ${ }^{6}$ Department of Clinical Epidemiology, Aarhus University Hospital, Aarhus, Denmark.

${ }^{7}$ Department of Cardiology, Aarhus University Hospital, Brendstrupgaardsvej 100, 8200 Aarhus N, Denmark.

\section{Authors' contributions}

$\Pi$ : analysis, interpretation of data, drafting the manuscript. MM: conception and design, acquisition of data, analysis, interpretation of data, revision of manuscript. JFL: conception and design, acquisition of data, analysis, interpretation of data, revision of manuscript. AK: conception and design, acquisition of data, analysis, interpretation of data, revision of manuscript LOJ: conception and design, acquisition of data, analysis, interpretation of data, revision of manuscript. JR: conception and design, acquisition of data, analysis, interpretation of data, revision of manuscript. PT: conception and design, acquisition of data, analysis, interpretation of data, revision of manuscript. SG: conception and design, acquisition of data, analysis, interpretation of data, revision of manuscript. EHC: conception and design, acquisition of data, analysis, interpretation of data, revision of manuscript. TE: conception and design, acquisition of data, analysis, interpretation of data, revision of manuscript. MM: conception and design, analysis, interpretation of data, revision of manuscript. LT: conception and design, acquisition of data, analysis, interpretation of data, revision of manuscript. HHT: conception and design, acquisition of data, analysis, interpretation of data, revision of manuscript. All authors read and approved the final manuscript.

\section{Competing interests}

MM has received lecture fees from Cordis, and consultant fees from Medtronic. JFL has received consultant fees from Boston Scientific, Guidant, Abbott, Terumo, St Jude medical and Cordis, and has received unrestricted research grant support from Abbott, Boston Scientific, Cordis, Medtronic, St Jude medical and Terumo. AK has received lecture fees from Cordis. LOJ has received lectures fees from Abbott and Cordis. JR has received consultant fees from Abbott and Cordis, and has received unrestricted research grant support from Abbott, Boston Scientific, Cordis, Medtronic and Terumo. LT has received lecture fees from Medtronic, Abbott, Cordis, and Boston Scientific; he also received consultant fees from Abbott and he is on the advisory board of Boston Scientific, and has received unrestricted research grant support from Medtronic, Abbott, Cordis, and Boston Scientific. All other authors declared no conflicts of interest.

Received: 20 November 2011 Accepted: 19 March 2012 Published: 19 March 2012

\section{References}

1. Wijns W, Kolh P, Danchin N, Di MC, Falk V, Folliguet T, Garg S, Huber K, James S, Knuuti J, et al: Guidelines on myocardial revascularization: The Task Force on Myocardial Revascularization of the European Society of Cardiology (ESC) and the European Association for Cardio-Thoracic Surgery (EACTS). Eur Heart J 2010, 31:2501-2555.

2. Serruys PW, Morice MC, Kappetein AP, Colombo A, Holmes DR, Mack MJ, Stahle E, Feldman TE, van den Brand M, Bass EJ, et al: Percutaneous coronary intervention versus coronary-artery bypass grafting for severe coronary artery disease. N Engl J Med 2009, 360:961-972.

3. Kandzari DE, Leon MB, Popma JJ, Fitzgerald PJ, O'Shaughnessy C, Ball MW, Turco M, Applegate RJ, Gurbel PA, Midei MG, et al: Comparison of zotarolimus-eluting and sirolimus-eluting stents in patients with native coronary artery disease: a randomized controlled trial. J Am Coll Cardiol 2006, 48:2440-2447.

4. Windecker $S$, Remondino A, Eberli FR, Juni $P$, Raber $L$, Wenaweser $P$, Togni M, Billinger M, Tuller D, Seiler C, et al: Sirolimus-eluting and paclitaxel-eluting stents for coronary revascularization. $N$ Engl J Med 2005, 353:653-662 
5. Rasmussen K, Maeng M, Kaltoft A, Thayssen P, Kelbaek H, Tilsted HH, Abildgaard U, Christiansen EH, Engstrom T, Krusell LR, et al: Efficacy and safety of zotarolimus-eluting and sirolimus-eluting coronary stents in routine clinical care (SORT OUT III): a randomised controlled superiority trial. Lancet 2010, 375:1090-1099.

6. Park DW, Kim YH, Yun SC, Kang SJ, Lee SW, Lee CW, Park SW, Seong IW Lee JH, Tahk SJ, et al: Comparison of zotarolimus-eluting stents with sirolimus- and paclitaxel-eluting stents for coronary revascularization: the ZEST (comparison of the efficacy and safety of zotarolimus-eluting stent with sirolimus-eluting and paclitaxel-eluting stent for coronary lesions) randomized trial. J Am Coll Cardiol 2010, 56:1187-1195.

7. Garg S, Serruys PW: Coronary stents: current status. J Am Coll Cardiol 2010, 56:S1-42.

8. Charlson ME, Pompei P, Ales KL, Mackenzie CR: A new method of classifying prognostic comorbidity in longitudinal studies: Development and validation. Journal of Chronic Diseases 1987, 40:373-383.

9. Charlson M, Szatrowski TP, Peterson J, Gold J: Validation of a combined comorbidity index. J Clin Epidemiol 1994, 47:1245-1251.

10. Kaltoft A, Jensen LO, Maeng M, Tilsted HH, Thayssen P, Bottcher M, Lassen JF, Krusell LR, Rasmussen K, Hansen KN, et al: 2-year clinical outcomes after implantation of sirolimus-eluting, paclitaxel-eluting, and bare-metal coronary stents: results from the WDHR (Western Denmark Heart Registry). J Am Coll Cardiol 2009, 53:658-664.

11. Tunstall-Pedoe H, Kuulasmaa K, Amouyel P, Arveiler D, Rajakangas AM, Pajak A: Myocardial infarction and coronary deaths in the World Health Organization MONICA Project. Registration procedures, event rates, and case-fatality rates in 38 populations from 21 countries in four continents. Circulation 1994, 90:583-612.

12. Sørensen HT: Regional administrative health registries as a resource in clinical epidemiology. International Journal of Risk and Safety in Medicine 1997, 10:1-22.

13. Andersen TF, Madsen M, Jorgensen J, Mellemkjoer L, Olsen JH: The Danish National Hospital Register. A valuable source of data for modern health sciences. Dan Med Bull 1999, 46:263-268.

14. Juel K, Helweg-Larsen K: The Danish registers of causes of death. Dan Med Bull 1999, 46:354-357.

15. Frank L: Epidemiology. When an entire country is a cohort. Science 2000, 287:2398-2399.

16. Madsen M, Davidsen M, Rasmussen S, Abildstrom SZ, Osler M: The validity of the diagnosis of acute myocardial infarction in routine statistics: a comparison of mortality and hospital discharge data with the Danish MONICA registry. J Clin Epidemiol 2003, 56:124-130.

17. Pedersen CB, Gotzsche H, Moller JO, Mortensen PB: The Danish Civil Registration System. A cohort of eight million persons. Dan Med Bull 2006, 53:441-449.

18. Hill AB: The environment and disease: association or causation? Proc $R$ Soc Med 1965, 58:295-300.

19. Stone GW, Midei M, Newman W, Sanz M, Hermiller JB, Williams J, Farhat N, Caputo R, Xenopoulos N, Applegate R, et al: Randomized comparison of everolimus-eluting and paclitaxel-eluting stents: two-year clinical followup from the Clinical Evaluation of the Xience V Everolimus Eluting Coronary Stent System in the Treatment of Patients with de novo Native Coronary Artery Lesions (SPIRIT) III trial. Circulation 2009, 119:680-686.

20. Applegate RJ, Hermiller JJ, Sanz M, Doostzadeh J, Pierson W, Su X, Lansky AJ, Sudhir K, Stone GW: Comparison of everolimus-eluting and paclitaxel-eluting coronary stents in patients with two treated vessels: 2year results from the SPIRIT III randomised trial. Eurolntervention 2010, 6:437-446.

21. Serruys PW, Silber S, Garg S, van Geuns RJ, Richardt G, Buszman PE, Kelbaek H, van Boven AJ, Hofma SH, Linke A, et al: Comparison of zotarolimus-eluting and everolimus-eluting coronary stents. N Engl J Med 2010, 363:136-146.

22. Galloe AM, Thuesen L, Kelbaek H, Thayssen P, Rasmussen K, Hansen PR, Bligaard N, Saunamaki K, Junker A, Aaroe J, et al: Comparison of paclitaxeland sirolimus-eluting stents in everyday clinical practice: the SORT OUT II randomized trial. JAMA 2008, 299:409-416.

\section{Pre-publication history}

The pre-publication history for this paper can be accessed here: http://www.biomedcentral.com/1471-2261/12/18/prepub

doi:10.1186/1471-2261-12-18

Cite this article as: Thim et al:: Clinical outcomes after treatment of multiple lesions with zotarolimus-eluting versus sirolimus-eluting coronary stents (a SORT OUT III substudy). BMC Cardiovascular Disorders $201212: 18$

\section{Submit your next manuscript to BioMed Central and take full advantage of:}

- Convenient online submission

- Thorough peer review

- No space constraints or color figure charges

- Immediate publication on acceptance

- Inclusion in PubMed, CAS, Scopus and Google Scholar

- Research which is freely available for redistribution

Submit your manuscript at www.biomedcentral.com/submit
Ciomed Central 